\title{
Interventions for Children Affected by Armed Conflict: a Systematic Review of Mental Health and Psychosocial Support in Low- and Middle-Income Countries
}

\author{
Mark J. D. Jordans ${ }^{1,2} \cdot$ Hugo Pigott ${ }^{1,3} \cdot$ Wietse A. Tol $^{4}$ \\ Published online: 14 January 2016 \\ (C) The Author(s) 2016. This article is published with open access at Springerlink.com
}

\begin{abstract}
Over one billion children under the age of 18 live in countries affected by armed conflict. This systematic review replicates an earlier study, aiming to provide a comprehensive update of the most current developments in interventions for children affected by armed conflict. For the period 20092015, a total of 1538 records were collected from PubMed, PsycINFO, and PILOTS. Twenty-four studies met the inclusion criteria, and the included interventions involve data from 4858 children. Although the number of publications and level of evidence has improved since the previous review, there is still a general lack of rigor and clarity in study design and reported results. Overall, interventions appeared to show promising results demonstrating mostly moderate effect sizes on mental health and psychosocial well-being. However, these positive intervention benefits are often limited to specific subgroups. There is a need for increased diversification in research focus, with more attention to interventions that focus at strengthening community and family support, and to young children, and improvements in targeting and conceptualizing of interventions.
\end{abstract}

This article is part of the Topical Collection on Child and Family Disaster Psychiatry

Mark J. D. Jordans

mark.jordans@kcl.ac.uk

1 Center for Global Mental Health, Institute of Psychology, Psychiatry \& Neuroscience, King's College London, London, UK

2 Research and Development Department, War Child Holland, Amsterdam, the Netherlands

3 Center for Global Mental Health, London School of Hygiene and Tropical Medicine, London, UK

4 Department of Mental Health, Johns Hopkins Bloomberg School of Public Health, Baltimore, USA
Keywords Armed conflict · Children · Evidence base · Systematic review $\cdot$ Violence $\cdot$ War

\section{Introduction}

Over one billion children under the age of 18 live in countries affected by armed conflict [1]. In 2013, 33 armed conflicts were recorded, with the majority in Africa (39\%), Asia (39\%), and the Middle East (12\%) [2]. These conflicts take place principally in "lower and middle-income countries" (LMIC), where $90 \%$ of the world's population of children and adolescents live.

Mental health and psychosocial well-being in settings of armed conflict are threatened by exposure to violence and other risk factors for mental health such as increased poverty and lack of access to basic services for example healthcare, education, housing, water, and sanitation [3]. In an armed conflict situation, the population is affected in various ways and consequently requires different kinds of support. International consensus guidelines, such as the Inter-Agency Standing Committee (IASC) guidelines for mental health and psychosocial support (MHPSS) in emergencies, agree on the need for a multi-layered system of support that is delivered at different levels of social and health systems [4]. The framework emphasizes integrating different forms of support, ranging from activities for the population as a whole (for example, providing general humanitarian support with respect to dignity and in a participatory manner), non-specialized activities that strengthen protective factors (for example, with a focus on strengthening informal social supports and existing coping mechanisms), and programs that address a smaller percentage of the population displaying significant psychological distress or mental disorders, for whom more specialized support is needed [5]. In public health terms, these interventions can be 
divided into promotion (i.e., activities aimed at strengthening positive aspects of mental health and well-being), prevention (i.e., activities aimed at making sure mental health problems do not develop, for example through action on the social determinants of mental health), and treatment (i.e., activities to reduce symptoms and improve functioning in people with identified mental disorders) [6].

Despite an increase in efforts to evaluate MHPSS for children and adolescents in areas of armed conflict, there remain important gaps in evidence [7]. A previous systematic review on psychosocial and mental health interventions for children in areas of armed conflict was published in 2009. That review concluded that there is a paucity of rigorous studies. Existing studies focused predominantly on PTSD as an outcome of interventions, and outcomes of evaluations were mixed. Given the time passed since this review, an update is timely [8]. Such an update may be useful in determining where the current focus of interventions lies and whether there are changes in types of interventions that are commonly implemented, as well as their effectiveness. For example, several authors have called in the past for paradigm shifts in MHPSS interventions for populations affected by armed conflict [9, 10]. Existing consensus guidelines broadly endorse proposed shifts away from a single focus on treatment of psychological symptoms to contextually appropriate multi-layered systems of support that build on existing resources. However, we previously did not find such broadening of interest reflected in the published peer-reviewed literature.

The purpose of this current systematic review is to assess the evidence of interventions since 2009, providing a current state of the art overview. The objective is to examine the type and effectiveness of psychosocial and mental health interventions for conflict-affected children. All study designs were assessed in order to broadly summarize the evidence for MHPSS.

\section{Method}

\section{Study Selection}

The inclusion and exclusion criteria for studies are listed in detail in Appendix 1. In summary, the review includes all studies that describe, and evaluate the effect of, psychosocial and mental health interventions for children affected by armed conflict in LMIC. The composite term MHPSS is used to describe any type of local or outside support that aims to protect or promote psychosocial well-being and/or prevent or treat mental disorder [4].

\section{Data Sources and Searches}

The search was restricted by language, publication status, and date. The following electronic databases were used: PubMed/
MEDLINE, PsycINFO, and PILOTS from January 1, 2009 to July 20, 2015. The following search terms were used: (child* OR adolescent*) AND (war* OR "community violence" OR "armed conflict") AND (mental health OR psychosocial) AND (intervention OR treatment). In addition, bibliographies of eligible papers were manually examined for relevant citations our searches missed. The authors of included studies were contacted in the event of missing data. After conducting the searches, we first screened all titles and abstracts for meeting inclusion and exclusion criteria outlined above (by HP and cross-checked by MJ). The remaining papers were fully read by two authors to check for papers including MHPSS interventions that assessed an outcome for children affected by armed conflict in LMIC.

\section{Data Extraction and Risk of Bias Assessment}

Data from these selected papers was obtained by using a previously developed [8] standard data extraction form. The study characteristics extracted were theoretical framework, specification of target groups and descriptions of interventions, treatment modalities, methodologies, and outcomes. The methodological quality of included studies was assessed by one person using the Cochrane risk of bias tool [11]. Risk of bias was assessed at both study and outcome levels.

\section{Data Synthesis and Analysis}

In accordance with our study aims, we conducted two types of analysis. First, for an account of intervention descriptions, we used thematic analysis to summarize themes, with a specific focus on cultural adaptations. Second, all evaluation studies reporting quantitative data were categorized into level of evidence ( 1 = randomized controlled trials, all types; 2 = quasiexperimental design and controlled studies; $3=$ noncontrolled design; 4 = case studies; adapted from Morris) [12]. Also, interventions were categorized according to the different levels of the pyramid of the IASC guidelines for mental health and psychosocial support in emergencies (i.e., social considerations in basic services and security, strengthening community and family supports, focused nonspecialized support, specialized services) [4]. To summarize quantitative evaluation studies, Cohen's $d$ effect size calculations were used to obtain an indication of strength of intervention benefits and allow for a comparison of the strength of intervention benefits (or harms) across interventions. Effect sizes were not adjusted for effects of clustering in cluster randomized trials. Effect sizes were graded as less than 0.30 small, 0.30 to 0.60 moderate, and above 0.60 large [13]. The validity of the quantitative evaluation studies was assessed using the Cochrane risk of bias tool [11]. It includes categorical variables $1-7$ to quantify selection bias consisting of random sequence generation and allocation concealment (1-2, 
respectively), performance bias comprising of blinding of participants and personnel (3), detection bias consisting of blinding of outcome assessment (4), attrition bias detailing incomplete outcome data (5), reporting bias comprising of selective reporting (6), and other sources of bias consisting of uncovered problems (7). These categorical variables were scored by low risk, high risk, and unclear risk. The methodology and results are presented according to the PRISMA statement for reporting systematic reviews [14].

\section{Results}

Figure 1 shows the screening and selection procedure for this review. A total of 1538 records were collected from three databases. Twenty-four studies met the inclusion criteria. Four studies used the same data set [15-18]. Table 1 provides an overview of all included studies.

\section{Delivery and MHPSS Approach ${ }^{1}$}

The collection of publications focuses on armed conflicts in nine countries, with $46 \%(n=11)$ of the studies taking place in Asia, $46 \%(n=11)$ in Africa, $4 \%(n=1)$ in Europe, and $4 \%$ $(n=1)$ in a collection of countries. The included 24 publications identified in peer-reviewed journals had the following study designs: five individually randomized controlled trials (RCTs), nine cluster randomized controlled studies, three controlled studies, four non-controlled studies, and three case studies. One case study summarized results of a collection of studies and reported high levels of client satisfaction, moderate post-treatment problem reductions, and significant levels of distress for service providers [19]. It was included in the analysis but excluded from calculating percentages below.

The included quantitative evaluation studies interventions involved data being collected with 4858 children, with just under two thirds $(60 \%, n=12)$ using a school as a delivery platform and over a third $(40 \%, n=8)$ implemented in community settings. The interventions consisted of $30 \%(n=6)$ MHPSS level 2 activities, $65 \%(n=13)$ level 3, and $5 \%$ $(n=1)$ level 4 initiatives. A non-specialist (a service provider who did not receive years of training is specialized care) delivered $90 \%$ of these interventions. The duration varied with $55 \%(n=11)$ implemented in 15 sessions or more, $5 \%(n=1)$ had ten to 14 sessions, $30 \%(n=6)$ less than ten sessions, and $10 \%(n=2)$ did not record the number of sessions. Training of a delivery agent was stated in $95 \%(n=19)$ of interventions. Eight programs included less than 1 month's training for the

\footnotetext{
${ }^{1}$ When calculating percentages of interventions, we have used $n=20$ as four publications report on the same intervention and one case study reported multiple interventions. For the calculation of percentages of publications, $n=23$ is used, not including the one with multiple results on multiple interventions.
}

delivery agent; however, these were for individuals with extensive prior experience working with the study population. Three interventions included 3 months of training. Of all programs, $55 \%(n=11)$ included supervision in order to support those implementing interventions and ensure fidelity to the program. There were seven interventions (35\%) that implemented MHPSS regardless of children's symptoms (universally), and 13 used a context-sensitive screener (65\%), principally for those demonstrating traumatic stress reactions.

The interventions targeted post-traumatic stress symptoms (PTSS), internalizing symptoms (depression, anxiety), and behavioral and emotional problems more generally (e.g., conduct problems). Eighteen publications (78\%) reported results on multiple outcome indicators. Of the 11 publications (48\%) that have PTSS as a primary outcome, ten included multiple indicators for internalizing symptoms and behavioral and emotional problems. Two case studies examined potential mechanisms of effective counseling and were delivered on an individual basis [20,21]. Almost all programs were group based ( $n=18,90 \%$ ), except for two interventions that included both group and individual elements $[22 \bullet \bullet, 23 \bullet \bullet]$. A multilevel multi-country program that took a public health approach was reported in eight publications [19-21, 24, 25••, 26-28]. This multi-level multi-country program targeted children with elevated psychosocial distress upon primary screening who were offered a classroom-based intervention. Those in need of more individualized or specialized care were referred for counseling and psychiatric care if available. Ten interventions involved the family or community in any capacity [21, 22••, 23••, 25••, 29-34].

\section{Evidence Base}

All publications reported positive promotion, prevention, and treatment effects on a range of indicators. Eighteen studies (78 \%) reported positive effects on their primary outcomes $[16,18,22 \bullet \bullet, 23 \bullet \bullet, 25 \bullet, 26-35,36 \bullet \bullet, 37,38]$, and eight (44\%) of these 18 showed positive impacts on specific subgroups $[16,18,26-28,30,31,36 \bullet \bullet]$. Therefore, only ten publications $(43 \%)$ reported positive overall promotion, prevention, and treatment effects on symptom reduction and improved well-being for their primary outcomes.

Improvements were shown on multiple outcome indicators for $16(70 \%)$ studies [15-18, 22••, 23••, 24, 25••, 26-28, $33-35,37,38]$. Most positive effects were small or moderate in size, with a few studies reporting large effect sizes. Traumafocused cognitive behavioral therapy (TF-CBT) was used to alleviate distress, for both sexually exploited girls and waraffected boys in Democratic Republic of the Congo, and demonstrated large effect sizes ( $d=2.13$ to $2.75[22 \bullet \bullet], d=0.64$ to $\left.2.01\left[23^{\bullet}\right]\right)$. A traumatic grief psychotherapy in Palestine resulted in significant improvements in PTSS and depression symptoms also with large effect sizes $(d=0.62-2.38)$ [38]. 
Fig. 1 Study flowchart

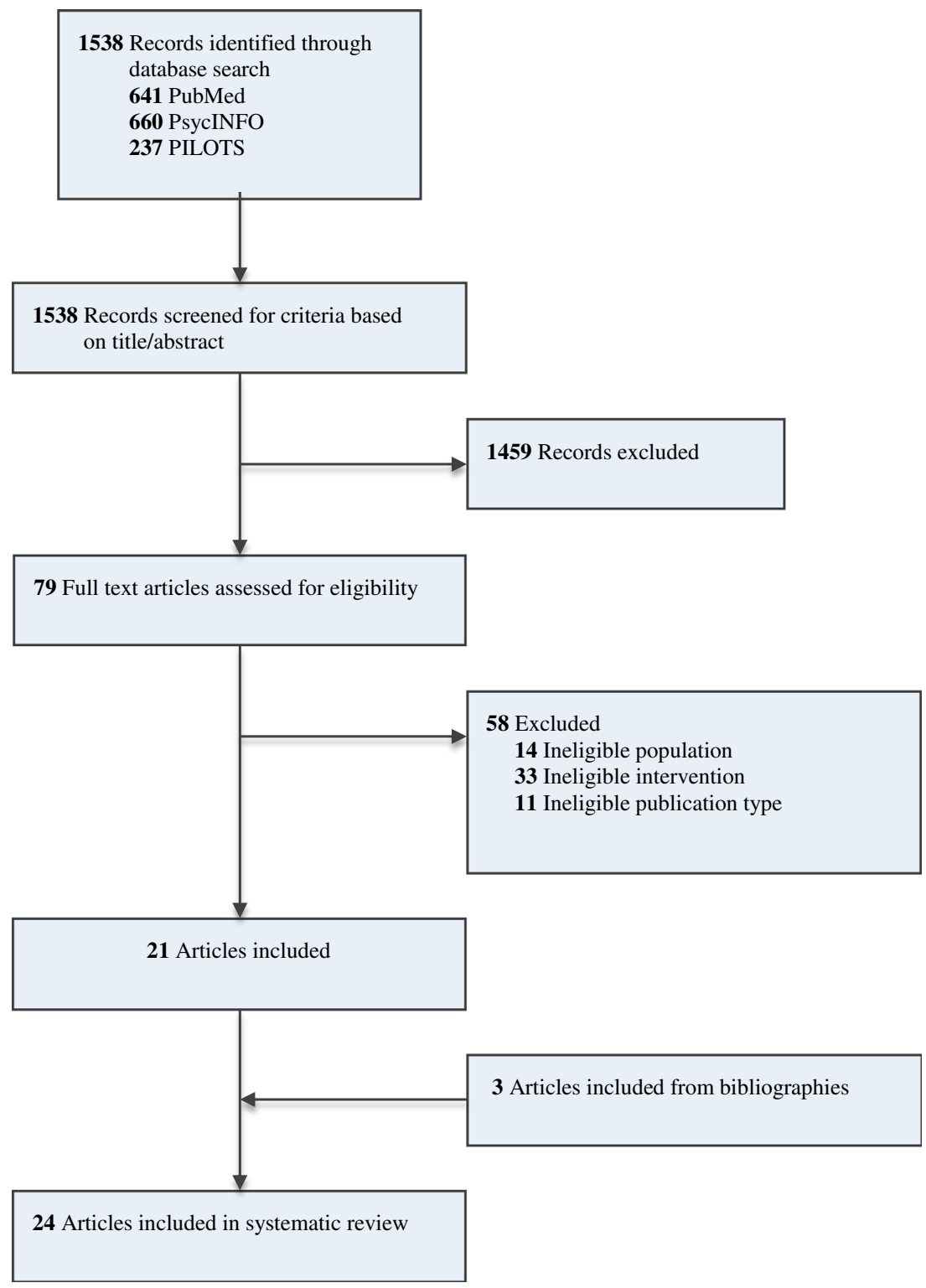

Five $(22 \%)$ publications identified negative outcomes. Gender and abduction history interacted to moderate the effectiveness of group interpersonal psychotherapy (GIPT) with a small negative outcome on male nonabducted subjects in regards to depression [36••]. There were increased PTSS in the experimental group compared to control, post-intervention in the student mediation program in Palestine [37]. A "Teaching Recovery Technique" aiming to improve emotion regulation (ER) and coping abilities actually established that a decrease in ER was associated with improved mental health and psychosocial well-being [17]. Gender-specific outcomes demonstrated that girls had greater reduction in PTSS in the waitlist control, compared to the experimental group in a classroom-based intervention in Sri Lanka [28]. The same intervention implemented in Burundi also reported negative effects for subgroups of children (depending on age, household composition, exposure, and displacement), with a better outcome for hope and functioning in the waitlist control compared to the experimental group [27].

\section{Intervention Modalities}

Figure 2 outlines the range of intervention modalities mapped on to the multi-layered approach as advocated by the IASC guidelines. The most frequently mentioned modalities were creative expressive, psycho-educational, and cognitive behavioral strategies. Creative expressive approaches emphasized interactive activities such as drama, music, role-playing, and drawing. They aim to build better relationships and improve well-being. Three interventions had a core (as opposed to 


\begin{tabular}{|c|c|c|c|c|c|}
\hline 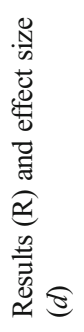 & 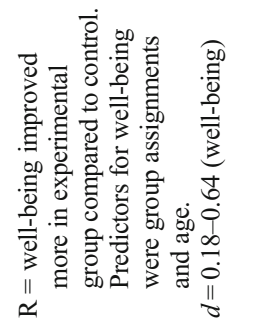 & 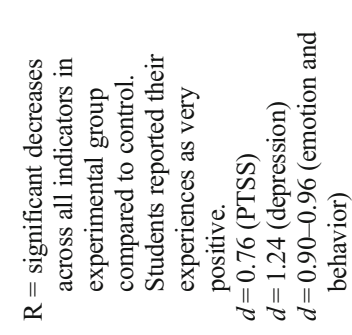 & 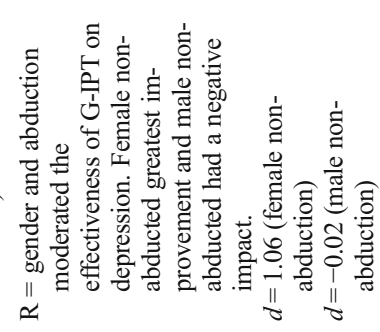 & 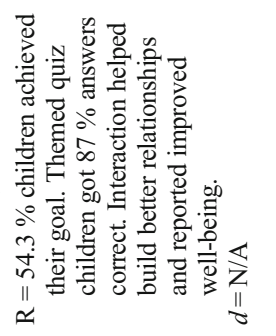 & 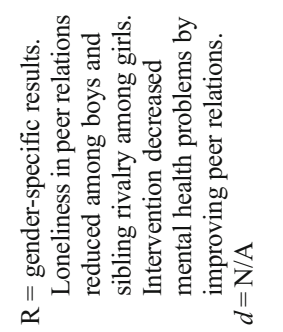 \\
\hline 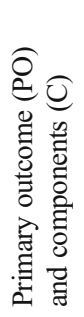 & 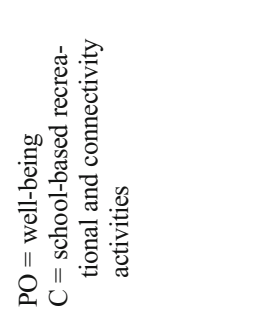 & 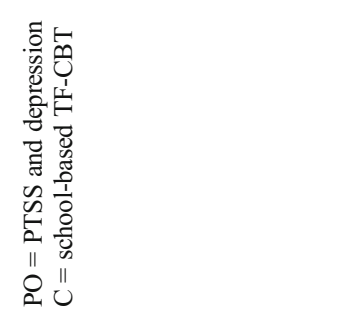 & 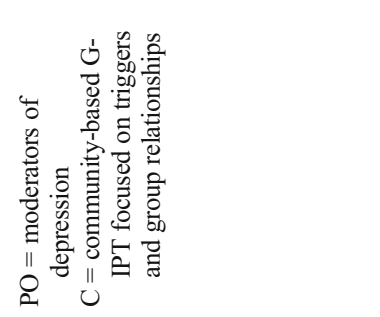 & 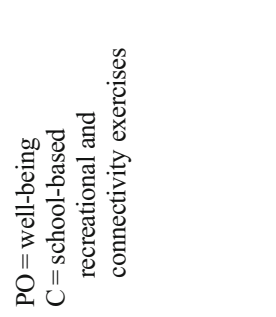 & 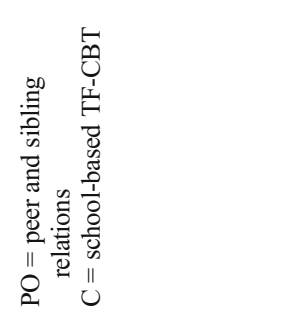 \\
\hline 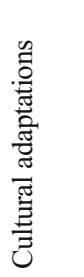 & 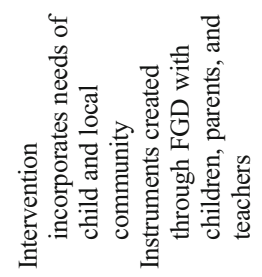 & 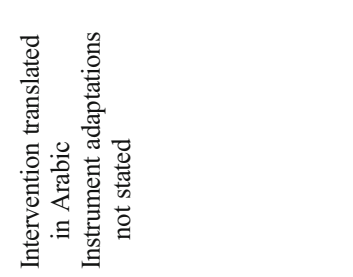 & 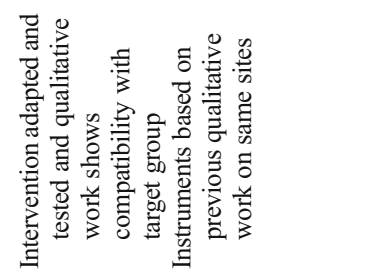 & 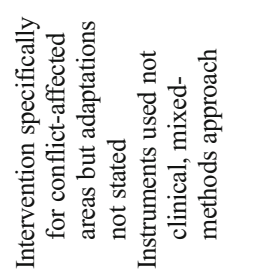 & 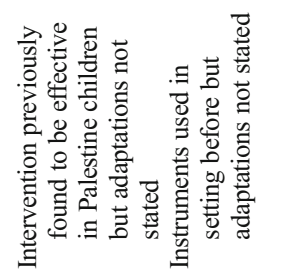 \\
\hline 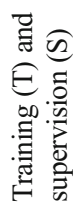 & 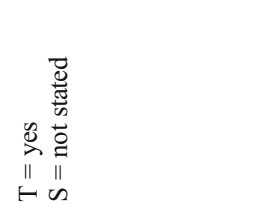 & 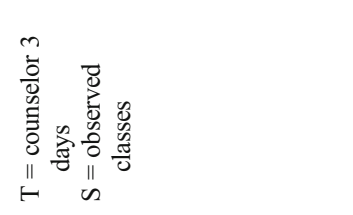 & 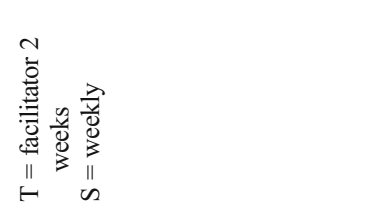 & 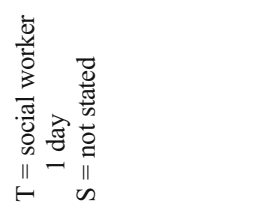 & 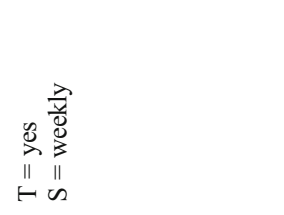 \\
\hline$\stackrel{\mathscr{m}}{\tilde{m}}$ & 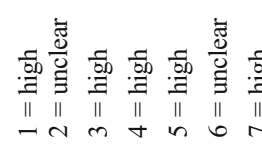 & 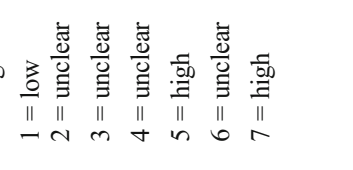 & 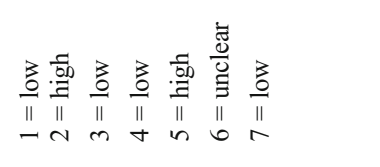 & 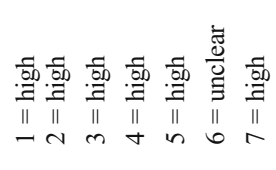 & 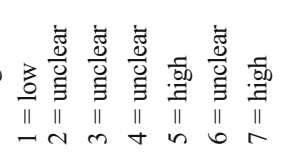 \\
\hline 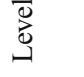 & $\sim$ & - & - & $m$ & \\
\hline$\frac{\vec{D}}{\stackrel{D}{0}}$ & 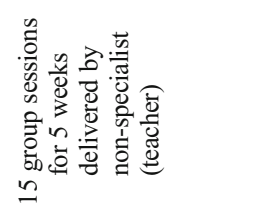 & 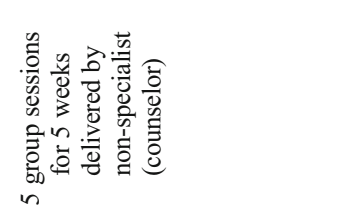 & 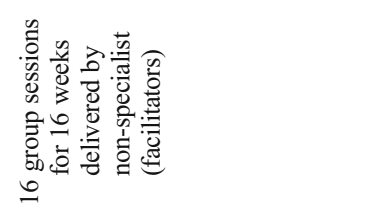 & 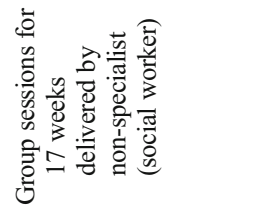 & 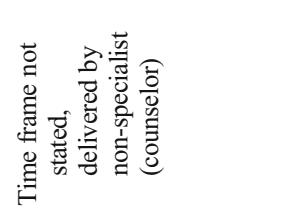 \\
\hline 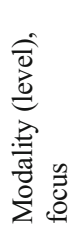 & 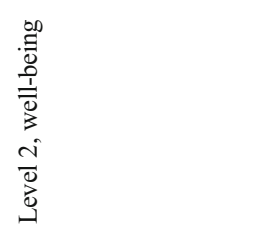 & 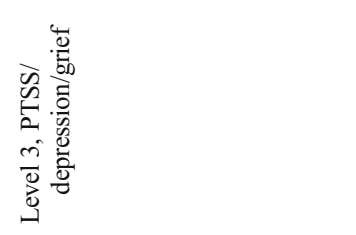 & 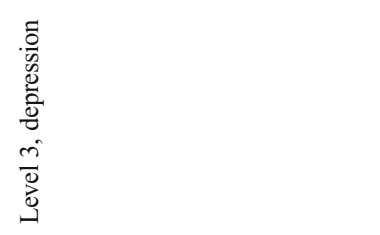 & 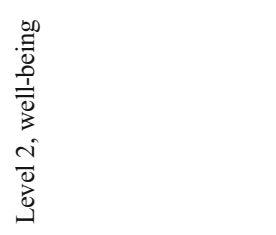 & 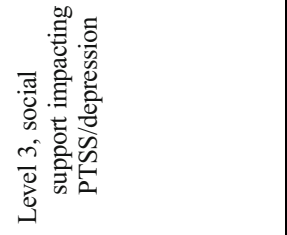 \\
\hline 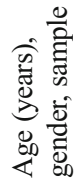 & 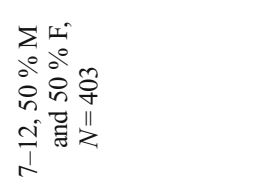 & 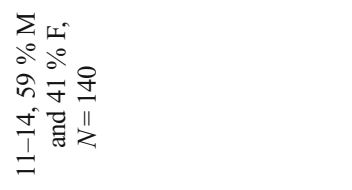 & 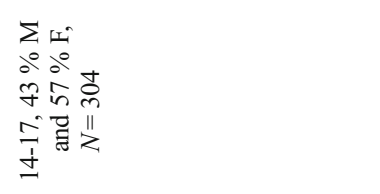 & 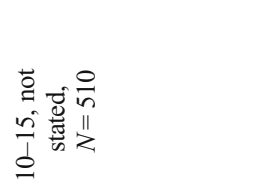 & 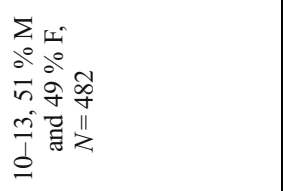 \\
\hline 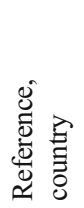 & 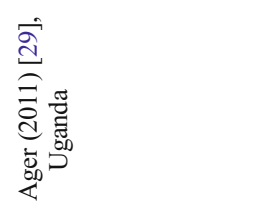 & 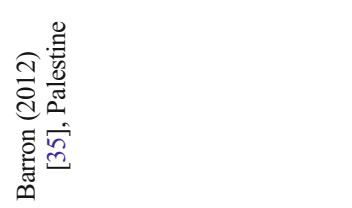 & 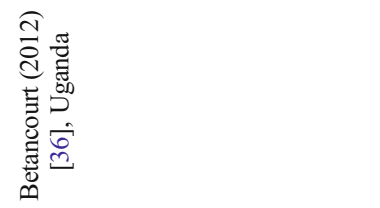 & 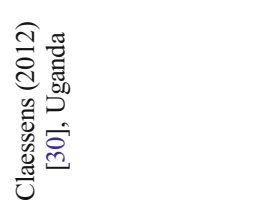 & 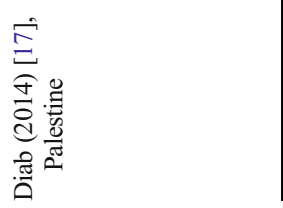 \\
\hline
\end{tabular}




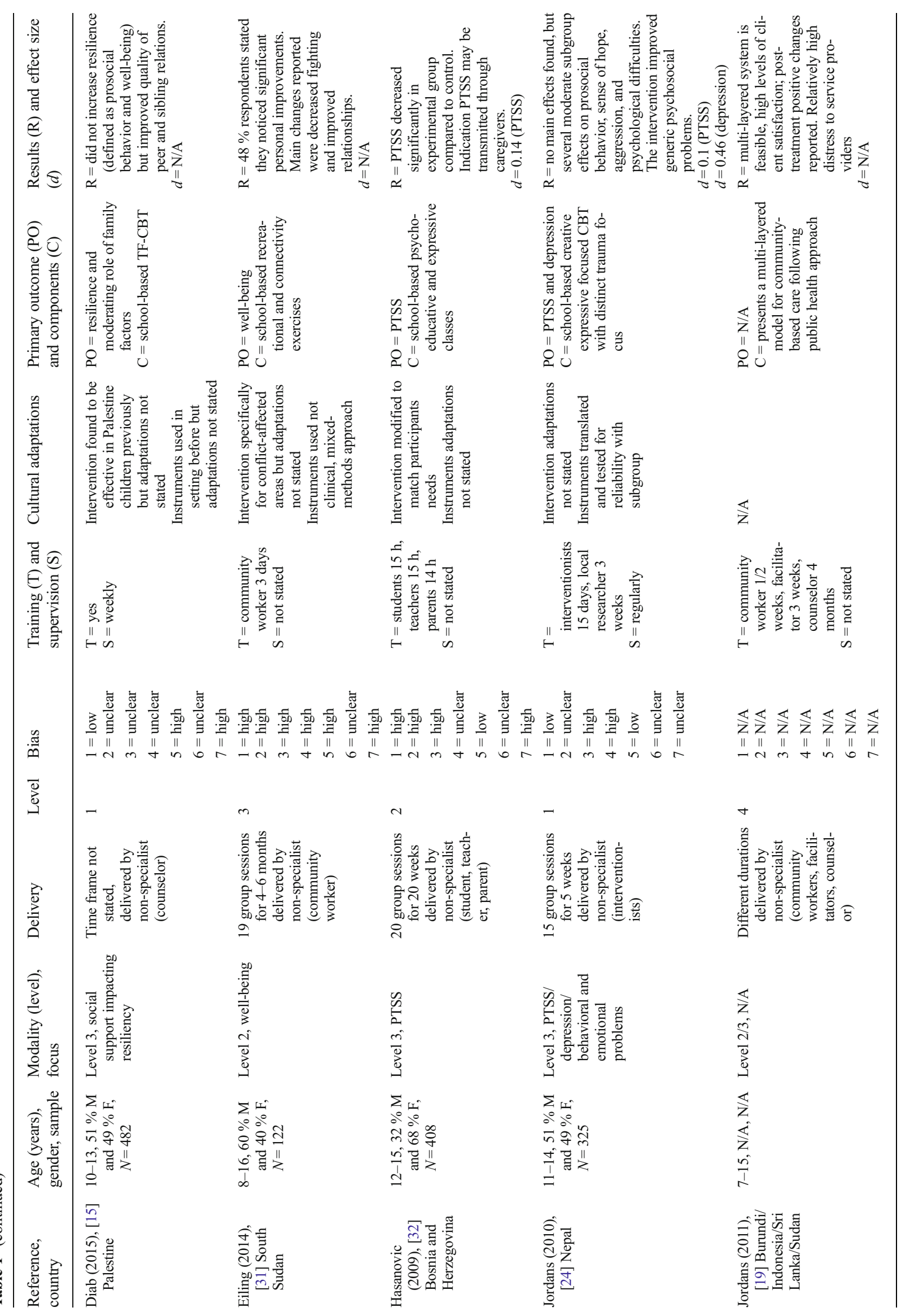




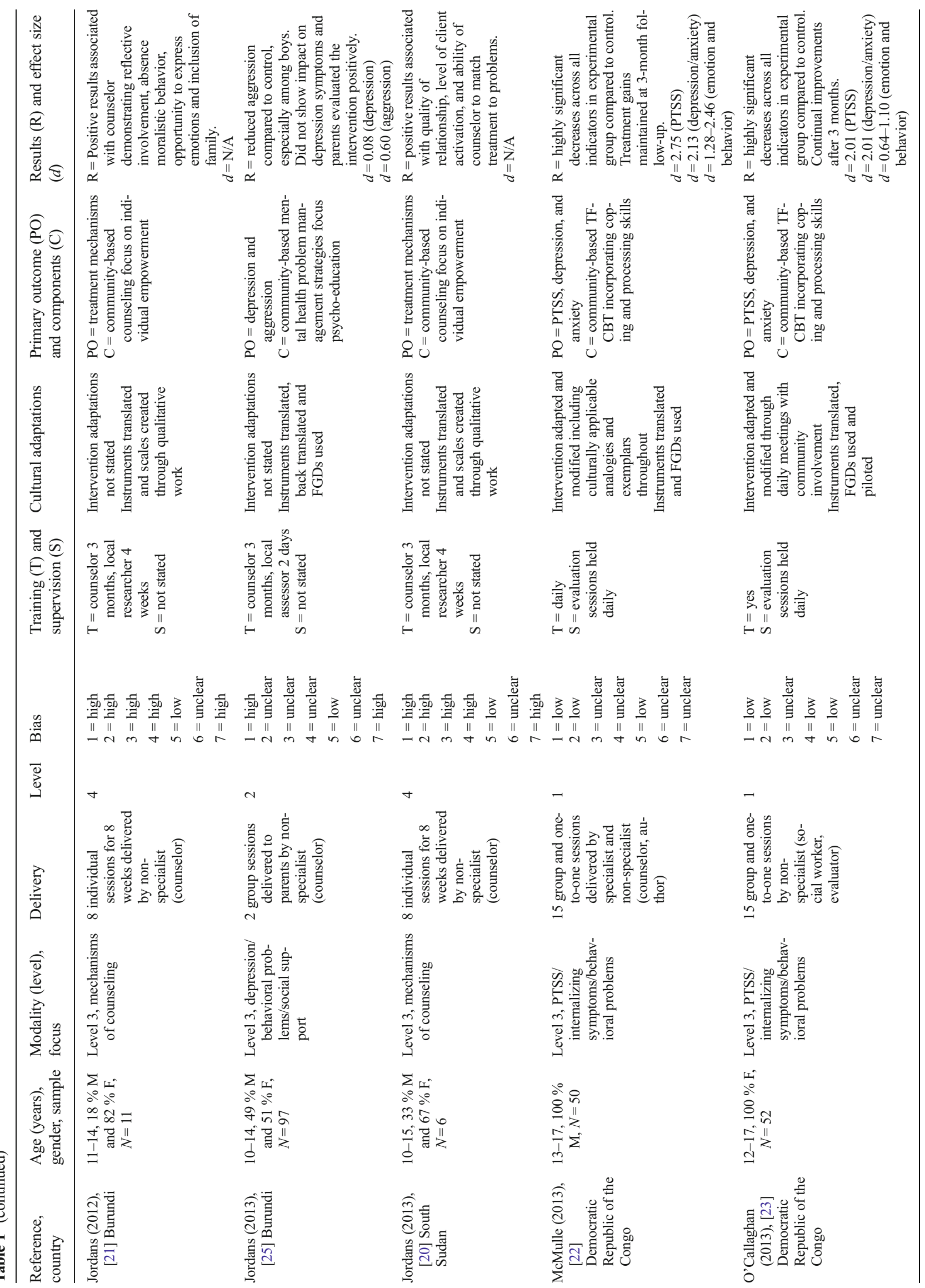




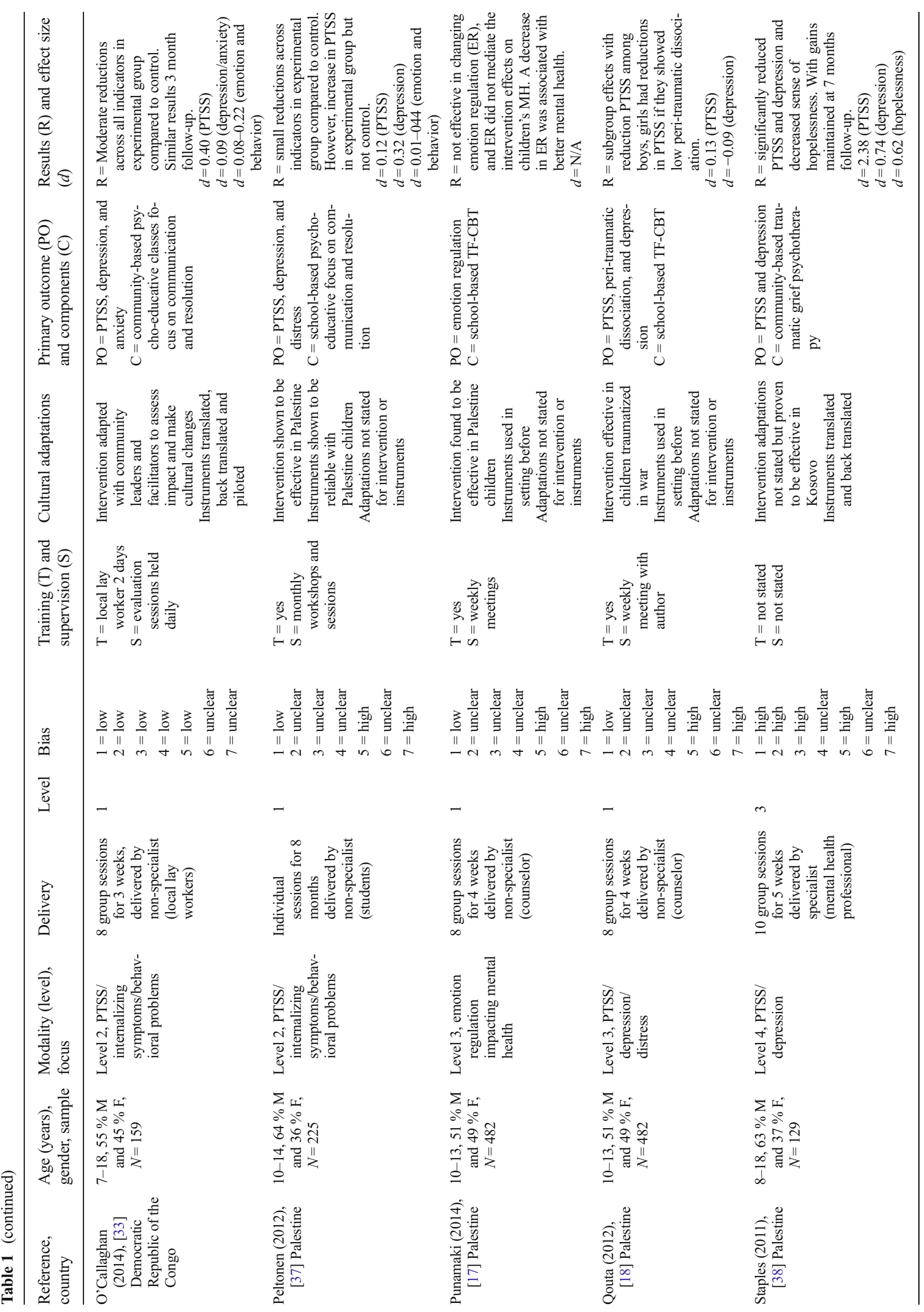




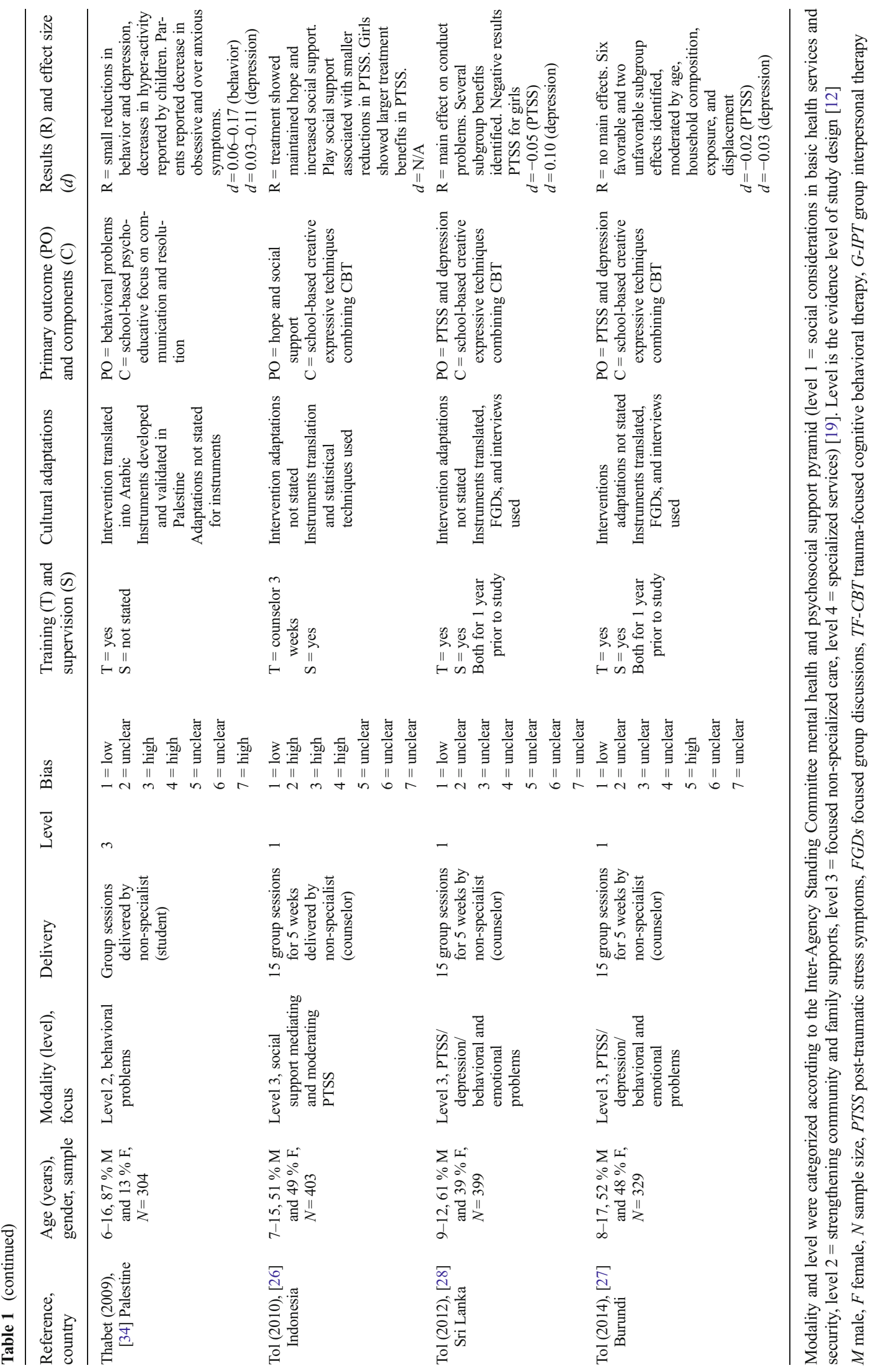


Fig. 2 Included interventions mapped onto care framework

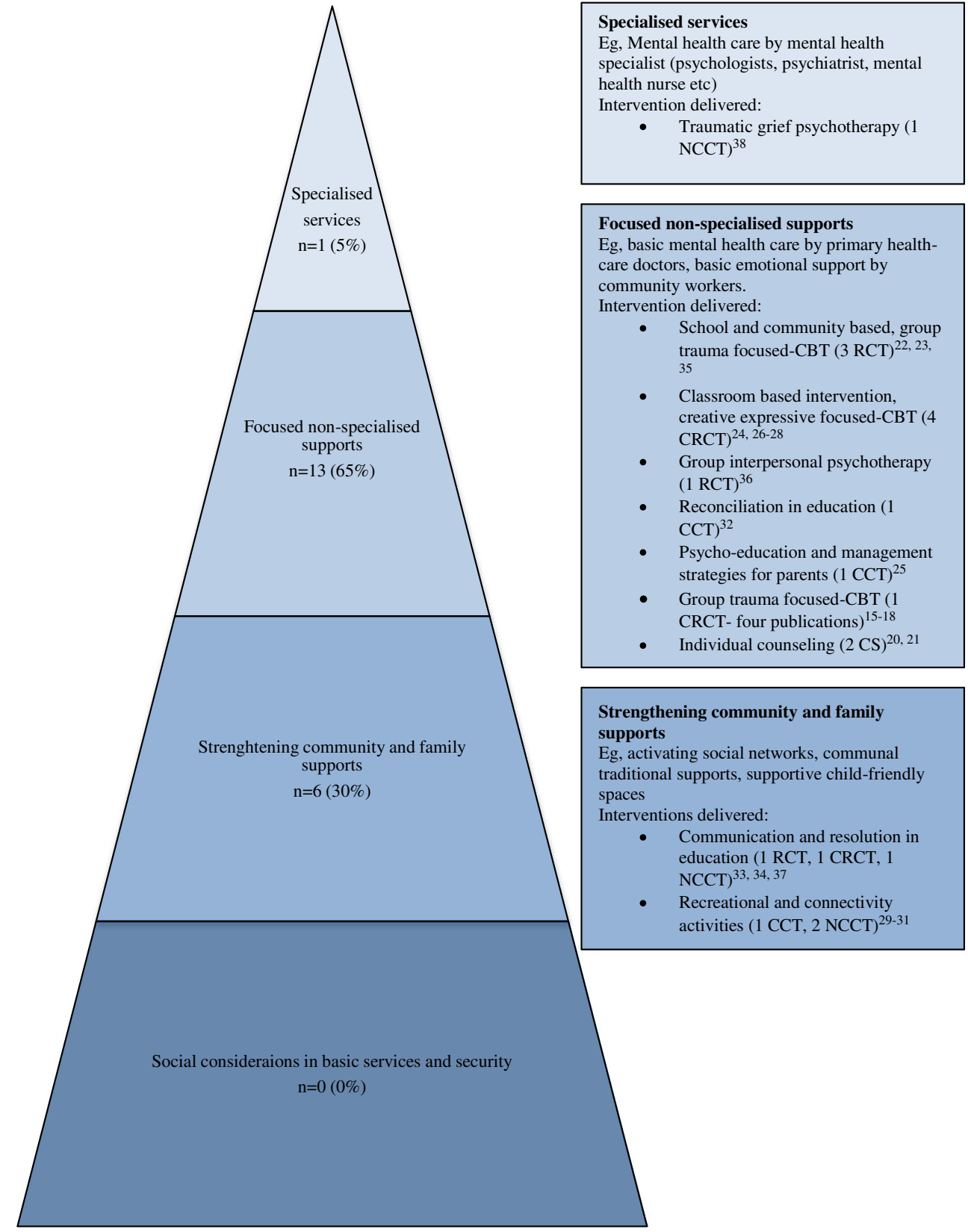

inclusive) focus on creative expressive activities [29-31]. The case studies that investigated counseling mechanisms used face-to-face engagement and supportive strategies centered on empowering the participant to reduce psychological and mental health problems [20, 21]. Other publications reported psycho-education and psychotherapies as strategies to improve the mental health and psychosocial well-being of children affected by armed conflict. Psycho-educational activities were implemented in five studies that focused on resilience, stress management, and conflict resolution [25••, 32-34, 37 ]. The psychotherapies targeting specific psychopathology re-

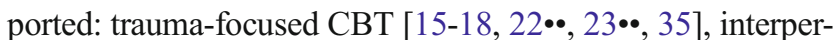
sonal psychotherapy [36••], traumatic grief psychotherapy
[38], and combined creative expressive activities with CBT [24, 26-28].

As can be seen in Fig. 2, there are no interventions in the dataset that focused on social considerations in basic humanitarian services and security, and a large majority of the programs investigated focused non-specialized support. Most mental health and psychosocial promotion interventions were school based. Only one study focused on the top level that represents the treatment of subgroups of children diagnosed with a mental health disorder who required more focused individualized care. A grief psychotherapy in Palestine as reported above aimed to treat those who were diagnosed with PTSD [38]. 
There were also two case studies evaluating treatment mechanisms of counseling in Burundi and South Sudan for children in need of individual-level care; however, counseling was provided by a non-specialist (hence included in the focused care level) [20,21]. Positive results were associated with an explicit trust formation and disclosure, active problem solving, structural trauma-focused exposure, family involvement, and parental support. Both studies reported displaying a moralistic attitude in counseling had a negative impact on a child's mental health and psychosocial well-being.

\section{Within Study Bias ${ }^{2}$}

The RCT(s) implemented in the Democratic Republic of the Congo were the only interventions to have low risk

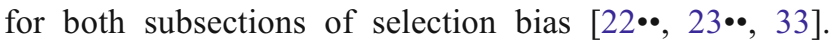
High risk and unclear risk of bias for blinding of the participants and personnel (performance bias) were coded in $50 \%(n=10)$ and $40 \%(n=8)$ of the interventions, respectively. Three publications (15\%) scored low for risk on blinding of outcome assessment (detection bias). Incomplete data representing loss to followup was coded as high risk in $45 \%(n=9)$ and unclear risk in $15 \%(n=3)$ of the interventions. Determining whether statistical results were selectively withheld from the publication was problematic to establish; consequently, reporting bias was coded as $100 \%$ unclear risk. Other sources of bias such as contamination of controls were determined to be $60 \%(n=12)$ high risk. Of the possible 140 high, low, and unclear risks of bias scores, $40 \%(n=56)$ were unclear and $39 \%(n=55)$ of scores were considered as high risk.

\section{Cultural Modifications and Key Themes}

With interventions delivered in nine different countries, it is important to review cultural adaptations. Instrument adaptations by translation and back translation, focus group discussions (FGD), and piloting were outlined in $60 \%(n=12)$ of the studies [20, 21, 22••, 23••, 24, 25••, 26-29, 33, 38]. Promotion, prevention, and treatment approaches were culturally modified in $40 \%(n=8)$ of the interventions [22••, 23••, 29, 32-35, $36 \bullet \cdot$. However, few gave detailed accounts of any actual adaptations made. The publications appeared to mainly report minor changes for instance translation of the manual and small alterations to session themes, making no changes to the

\footnotetext{
${ }^{2}$ Four studies used one data set; study bias was recorded from the original publication [18]; therefore, percentages are based on $n=20$ (publication with multiple interventions excluded).
}

overall structure of interventions. The interventions detailing their cultural adaptations such as culturally applicable analogies and examples throughout the modified program manual

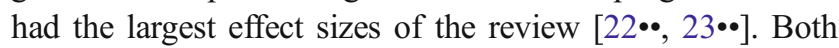
were randomized controlled trials.

Although $70 \%(n=16)$ of studies reported specific intervention effects in certain subgroups, only one study tailored their intervention by splitting groups by age and gender [33]. Fifty-two percent of the publications recommended that future interventions should apply multi-levelled approaches $[15,17$,

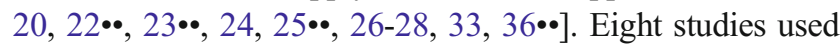
intervention approaches with a focus beyond children's individual symptomology, incorporating community/caregiver aspects $[21,22 \bullet \bullet, 23 \bullet \bullet, 25 \bullet \bullet, 29,30,32,33]$. The community/ caregiver aspects included helping the elderly, planting trees, psycho-educational classes for parents, a graduation ceremony attended by key figures in the community, and the creation of a community advisory board to assist with implementation. Feedback on treatment quality and satisfaction were only ascertained from children in $13 \%(n=3)$ of publications $[30,31,35]$. The delivery agent's relationship with the participant was described as integral to positive treatment effects in both publications on mechanisms of counseling [20,21]. However, only one study gave a rationale for their recruitment strategy $[23 \bullet \bullet]$.

\section{Discussion}

The results of this systematic review, covering the period 2009-2015, illustrate the current modalities and evidence of psychosocial and mental health interventions for children affected by armed conflict in LMIC.

\section{Summary}

All 24 identified publications reported positive benefits (i.e., promotion, prevention, or treatment) associated with evaluated interventions. However, under half (43\%) of these demonstrated an overall positive impact on their primary outcomes, and five studies $(22 \%)$ displayed negative effects. Therefore, the interventions may have improved some children's mental health but undermined the natural recovery of others. Most mental health and psychosocial interventions were school based, which as a group demonstrated mixed results. The evidence suggests that interventions often resulted in specific subgroup effects. The school-based interventions mainly reported smaller effect size impacts on symptom reduction of primary outcomes and more positive effects on secondary outcomes (mostly not disorder-specific outcomes, for example behavioral problem, or protective factors such as hope and social support). Nine different countries were 
included in the review; however, few cultural adaptations were made. Adapting interventions to the cultural context may lead to added impact, for example inviting community leaders and stakeholders in helping to design programs, thus being empowered with a voice in the design of the intervention that will match the communities' needs [39]. Although numerous publications detailed moderators and mediators of MHPSS, children and adolescents were rarely consulted for their experiences. Effects of individual counseling for children were moderated by the relationship the client had with their counselor, the structure and components of care, and family involvement and support.

\section{Comparison}

This updated systematic review detailed both differences and similarities to the previous systematic review conducted 5 years prior. There is a greater quantity of interventions evaluated in the updated review, with 24 studies identified over a 5-year period compared to a previous 12 studies (for the period 2009 and before). Using the classes of evidence by Morris that have been adapted, interventions were levels 1 or 2 for $70 \%(n=14)$ of studies, where previously it was $42 \%(n=5)$ [12]. This suggests an encouraging improvement in evidence for efficacy and effectiveness of MHPSS for children affected by armed conflict. The inclusion of stronger study designs assists in establishing causality between intervention approach and positive outcomes. However, only two of the current studies had majority low risk of bias scores; this reduces the potential validity of reported results from the included interventions [23••, 33]. Although the level of evidence from study design appears to have improved, there is still a lack of rigor for many of the evaluations. The process in which interventions are implemented also needs greater description, particularly with regards to cultural adaptation. There is a lack of clarity in reported study design, implementation, and results.

The results demonstrate moderate effect sizes in a large majority of the publications and a major focus on PTSD; this was also the case in the 2009 review. However, the current review also includes studies with large effects and most studies also assessed depression and/or behavioral problems. This may have been the result of the ongoing debate about interventions that solely focus on the individual's conflict exposure and PTSD symptoms, without also addressing broader risk and protective systems factors [7, 9, 10]. Per illustration, in Kabul, war exposure accounted for only $15 \%$ of the variance in PTSD symptom levels, and in Sri
Lanka, it was $8 \%$. Similarly, direct exposure accounted for $2 \%$ of the variance in distress levels in Palestinian youth and only $1 \%$ of the variance in PTSD symptom levels was attributable to the violence experienced in Sudan for Darfurian refugees in Chad [10]. A daily stressors model to outline these results indicated a need to incorporate environmental and societal factors when designing interventions. Multi-levelled interventions that incorporated a community-based approach were advocated in the previous review. Although a multi-levelled care package was included in the current review, few studies implemented an intervention that aimed to integrate into the existing local health or social systems (a strategy advocated to promote sustainability [40]). Multi-level interventions were much more represented in the current review; however, these publications all stem from one multi-country program [19-21, 24, 25••, 26-28].

\section{Implications}

There are continuing gaps in the literature that explores effectiveness of mental health and psychosocial support interventions for children affected by armed conflict. First, while most of the interventions being implemented in humanitarian settings are geared towards strengthening community support (e.g., activating social networks, supportive child-friendly spaces-level 2 in Fig. 2), most research attention still goes to focused interventions, especially CBT. More diversification in research focus is therefore called for. Few publications focus on parents and families. Given existing evidence of parenting interventions in high-income setting, and the promising results from the brief parenting psycho-education intervention in Burundi [25••], family-oriented interventions should be further explored. Specifically, as a focus on young children (below 6 years of age) is entirely lacking in the current review. Also, the role of physical activities in interventions may be further explored. Several systematic reviews have reported an association between physical activity and improved self-esteem, social interaction, and lower levels of depression and anxiety for children [41-43].

Second, although we find that there are overall positive benefits of evaluated intervention for subgroups of children, we also identified studies with negative impacts. In our opinion, this calls for better targeting and improved conceptual development of interventions. The described interventions often consisted of multiple elements and often focused on children in settings of armed conflict broadly. Nevertheless, publications rarely 
outlined how specific intervention elements were aimed at addressing specific paths of a causal pathway. Few intervention descriptions described a theory of change that outlined how interventions may affect different subgroups of children, even though interventions were implemented in complex and dynamic environments with ongoing adversity threatening mental health and wellbeing. Similarly, we found that interventions that had very different goals (ranging from promotion, to prevention, to treatment) often applied the same outcome measures, rather than select outcome measures that matched intervention goals. We feel that further sophistication in tailoring interventions to specific socio-cultural contexts and conflict settings could help mitigate the negative effects that were identified in the identified studies.

\section{Limitations}

A few limitations of the systematic review methodology should be noted. The review searched three databases and only peer-reviewed articles were included, excluding any gray literature. Primary outcomes were often not stated therefore they were assigned to categories based on the core intervention focus. Furthermore, publications targeting children and adults simultaneously were excluded if the majority of the sample was adult at the time of intervention, yet they still may yield important findings for the review. For example, a community-implemented intervention using narrative exposure therapy demonstrated positive results on former child soldiers even after a 1-year follow-up period [44]. The Cohen's $d$ effect sizes are established from a single postintervention time point, neglecting natural recovery and baseline differences between groups. Cohen's $d$ effect sizes can therefore be an under- or overestimate of the intervention effect.

\section{Conclusion}

Although the number of publications and level of evidence have improved, there is still a general lack of rigor and clarity in study and intervention design and reported results. Some interventions show promising results demonstrating mostly moderate effect sizes on mental health and psychosocial well-being, albeit often for subgroups. CBT-based interventions, and the school as the delivery platform, are the most commonly reported. There is a need for increased diversification in research focus, with more attention to interventions that focus at strengthening community and family support, and to young children, and improvements in targeting and conceptualizing of interventions.

\section{Compliance with Ethical Standards}

Conflict of Interest Mark J.D. Jordans, Hugo Pigott, and Wietse A. Tol declare that they have no conflict of interest.

Human and Animal Rights and Informed Consent This article does not contain any studies with human or animal subjects performed by any of the authors.

\section{Appendix 1}

Table 2 Inclusion and exclusion criteria for review

\begin{tabular}{|c|c|c|}
\hline & Included & Excluded \\
\hline Publication type & $\begin{array}{l}\text { Date (1 January 2009) to } \\
\text { (20 July 2015) } \\
\text { Only lower and middle- } \\
\text { income countries } \\
\text { (LAMIC) } \\
\text { Only studies reported in } \\
\text { English peer- } \\
\text { reviewed journals }\end{array}$ & \\
\hline Study design & All study designs & \\
\hline Study population & $\begin{array}{l}\text { Child and adolescent } \\
\text { population affected } \\
\text { by armed conflict }\end{array}$ & $\begin{array}{l}\text { Adult refugees in high- } \\
\text { income countries } \\
\text { (HIC) }\end{array}$ \\
\hline $\begin{array}{l}\text { Definition mental } \\
\text { health }\end{array}$ & $\begin{array}{l}\text { State of well-being in } \\
\text { which every individ- } \\
\text { ual can cope with the } \\
\text { stresses of life, can } \\
\text { work productively, } \\
\text { and is able to make a } \\
\text { contribution to their } \\
\text { community [45] }\end{array}$ & \\
\hline $\begin{array}{l}\text { Definition of mental } \\
\text { health and } \\
\text { psychosocial } \\
\text { support (MHPSS) }\end{array}$ & $\begin{array}{l}\text { MHPSS is used to } \\
\text { describe any type of } \\
\text { local or outside } \\
\text { support that aims to } \\
\text { protect or promote } \\
\text { psychosocial well- } \\
\text { being and/or prevent } \\
\text { or treat mental disor- } \\
\text { der [4] }\end{array}$ & $\begin{array}{l}\text { Interventions not } \\
\text { evaluated MHPSS } \\
\text { not specific to study } \\
\text { population }\end{array}$ \\
\hline $\begin{array}{l}\text { Definition of child } \\
\text { and adolescent }\end{array}$ & $\begin{array}{l}\text { A person of age } 18 \text { or } \\
\text { below }\end{array}$ & \\
\hline $\begin{array}{l}\text { Definition of armed } \\
\text { conflict }\end{array}$ & $\begin{array}{l}\text { Whenever there is a } \\
\text { resort to armed force } \\
\text { between states or } \\
\text { protracted armed } \\
\text { violence between } \\
\text { governmental } \\
\text { authorities and } \\
\text { organized armed } \\
\text { groups or between } \\
\text { such groups within a } \\
\text { state [46] }\end{array}$ & $\begin{array}{l}\text { Non-war-related } \\
\text { violence } \\
\text { Natural disasters }\end{array}$ \\
\hline Outcome & $\begin{array}{l}\text { Clinical outcomes } \\
\text { Psychosocial outcomes }\end{array}$ & \\
\hline
\end{tabular}


Open Access This article is distributed under the terms of the Creative Commons Attribution 4.0 International License (http:// creativecommons.org/licenses/by/4.0/), which permits unrestricted use, distribution, and reproduction in any medium, provided you give appropriate credit to the original author(s) and the source, provide a link to the Creative Commons license, and indicate if changes were made.

\section{References}

Papers of particular interest, published recently, have been highlighted as:

- Of importance

.. Of major importance

1. United Nations International Children's Emergency Fund (UNICEF), United Nations. Office of the Special Representative of the Secretary-General for Children Armed Conflict. Machel study 10-year strategic review: children and conflict in a changing world. New York: UNICEF; 2009.

2. Themner L, Wallensteen P. Armed conflicts, 1946-2013. J Peace Res. 2014;4(51):541-54.

3. World Bank. Mental health and conflicts: conceptual framework and approaches. Washington: World Bank; 2005.

4. Inter-Agency Standing Committee (IASC). IASC guidelines on mental health and psychosocial support in emergency settings. Geneva; 2007

5. United Nations. UNHCR'S mental health and psychosocial support for persons of concern Geneva. The UN refugee agency; 2013.

6. Tol WAP, M; Bass, J.K; Galappatti, A; Eaton, W. Mental health and psychosocial support in humanitarian settings: a public mental health perspective. Epidemiol Psychiatric Sci. 2015;24(6):484-94.

7. Tol WA, Barbui C, Galappatti A, Silove D, Betancourt TS, Souza $\mathrm{R}$, et al. Mental health and psychosocial support in humanitarian settings: linking practice and research. Lancet (London, England). 2011;378(9802):1581-91.

8. Jordans MJD, Tol WA, Komproe IH, De Jong JVTM. Systematic review of evidence and treatment approaches: psychosocial and mental health care for children in war. Child Adolesc Mental Health. 2009;14(1):2-14.

9. Miller KE, Kulkarni M, Kushner H. Beyond trauma-focused psychiatric epidemiology: bridging research and practice with waraffected populations. Am J Orthopsychiatry. 2006;76(4):409-22.

10. Miller KE, Rasmussen A. War exposure, daily stressors, and mental health in conflict and post-conflict settings: bridging the divide between trauma-focused and psychosocial frameworks. Soc Sci Med. 2010;70(1):7-16.

11. Higgins JPT GS. Cochrane handbook for systematic reviews of interventions version 5.1.0. www.cochrane-handbook.org. Cochrane; 2011.

12. Morris J, van Ommeren M, Belfer M, Saxena S, Saraceno B. Children and the sphere standard on mental and social aspects of health. Disasters. 2007;31(1):71-90.

13. Cohen J. Statistical power analysis for the behavioural sciences. 2nd ed. Erlbaum: Hillsdale; 1988.

14. Liberati A, Altman DG, Tetzlaff J, Mulrow C, Gotzsche PC, Ioannidis JP, et al. The PRISMA statement for reporting systematic reviews and meta-analyses of studies that evaluate healthcare interventions: explanation and elaboration. BMJ (Clin Res Ed). 2009;339:b2700.

15. Diab M, Peltonen K, Qouta SR, Palosaari E, Punamaki R-L. Effectiveness of psychosocial intervention enhancing resilience among war-affected children and the moderating role of family factors. Child Abuse Negl. 2015;40:24-35.

16. Diab M, Punamaki R-L, Palosaari E, Qouta SR. Can psychosocial intervention improve peer and sibling relations among war-affected children? Impact and mediating analyses in a randomized controlled trial. Soc Dev. 2014;23(2):215-31.

17. Punamaki R-L, Peltonen K, Diab M, Qouta SR. Psychosocial interventions and emotion regulation among war-affected children: randomized control trial effects. Traumatology. 2014;20(4):241-52.

18. Qouta SR, Palosaari E, Diab M, Punamaki R-L. Intervention effectiveness among war-affected children: a cluster randomized controlled trial on improving mental health. J Trauma Stress. 2012;25(3):288-98

19. Jordans MJ, Komproe IH, Tol WA, Susanty D, Vallipuram A, Ntamatumba $\mathrm{P}$, et al. Practice-driven evaluation of a multi-layered psychosocial care package for children in areas of armed conflict. Community Ment Health J. 2011;47(3):267-77.

20. Jordans M, Komproe I, Tol W, Nsereko J, de Jong J. Treatment processes of counseling for children in South Sudan: a multiple $\mathrm{n}=1$ design. Community Ment Health J. 2013;49(3):354-67.

21. Jordans MJ, Komproe IH, Smallegange E, Ntamatumba P, Tol WA, De Jong JT. Potential treatment mechanisms of counseling for children in Burundi: a series of $\mathrm{n}=1$ studies. Am J Orthopsychiatry. 2012;82(3):338-48.

22.• McMullen J, O'Callaghan P, Shannon C, Black A, Eakin J. Group trauma-focused cognitive-behavioural therapy with former child soldiers and other war-affected boys in the DR Congo: a randomised controlled trial. J Child Psychol Psychiatry. 2013;54(11):1231-4. Used cultural adaptations throughout the program and incorported physical activity reporting large effect sizes.

23.• O'Callaghan P, McMullen J, Shannon C, Rafferty H, Black A. A randomized controlled trial of trauma-focused cognitive behavioral therapy for sexually exploited, war-affected Congolese girls. J Am Acad Child Adolesc Psychiatry. 2013;52(4):359-69. Delivery agent had extensive experience working with study population. Cultural adaptations were made throughout the program and large effect sizes were reported. A graduation ceremony involving the family and representatives of civil society allowed for community acceptance of a stigmatised group.

24. Jordans MJ, Komproe IH, Tol WA, Kohrt BA, Luitel NP, Macy RD, et al. Evaluation of a classroom-based psychosocial intervention in conflict-affected Nepal: a cluster randomized controlled trial. J Child Psychol Psychiatry. 2010;51(7):818-26.

25.• Jordans MJ, Tol WA, Ndayisaba A, Komproe IH. A controlled evaluation of a brief parenting psychoeducation intervention in Burundi. Soc Psychiatry Psychiatr Epidemiol. 2013;48(11):18519. Demonstrated that a very short parental focused intervention can have a moderate impact on a child's mental health and psychosocial well being. Using parents as a delivery agent and the home as the platform of care is an area which needs further investigation.

26. Tol WA, Komproe IH, Jordans MJ, Gross AL, Susanty D, Macy $\mathrm{RD}$, et al. Mediators and moderators of a psychosocial intervention for children affected by political violence. J Consult Clin Psychol. 2010;78(6):818-28.

27. Tol WA, Komproe IH, Jordans MJ, Ndayisaba A, Ntamutumba P, Sipsma H, et al. School-based mental health intervention for children in war-affected Burundi: a cluster randomized trial. BMC Med. 2014;12:56

28. Tol WA, Komproe IH, Jordans MJ, Vallipuram A, Sipsma H, Sivayokan S, et al. Outcomes and moderators of a preventive school-based mental health intervention for children affected by war in Sri Lanka: a cluster randomized trial. World Psychiatry : Off J World Psychiatric Assoc (WPA). 2012;11(2):114-22. 
29. Ager A, Akesson B, Stark L, Flouri E, Okot B, McCollister F, et al. The impact of the school-based psychosocial structured activities (PSSA) program on conflict-affected children in Northern Uganda. J Child Psychol Psychiatry. 2011;52(11):1124-33.

30. Claessens F, Graaff D, Jordans MJ, Boer F, van Yperen T. Participatory evaluation of psychosocial interventions for children: a pilot study in Northern Uganda. Int JMental Health, Psychosocial Work Couns Area Armed Conflict. 2012;1(10):43-58.

31. Eiling E, Van Diggele-Holtland M, Van Yperen T, Boer F. Psychosocial support for children in the Republic of South Sudan: an evaluation outcome. Interv: J Mental Health Psychosocial Support Conflict Affected Area. 2014;12(1):61-75.

32. Hasanovic M, Srabovic S, Rasidovic M, Sehovic M, Hasanbasic E, Husanovic J, et al. Psychosocial assistance to students with posttraumatic stress disorder in primary and secondary schools in post-war Bosnia Herzegovina. Psychiatr Danub. 2009;21(4):463-73.

33. O'Callaghan P, Branham L, Shannon C, Betancourt TS, Dempster M, McMullen J. A pilot study of a family focused, psychosocial intervention with war-exposed youth at risk of attack and abduction in north-eastern Democratic Republic of Congo. Child Abuse Negl. 2014;38(7):1197-207.

34. Thabet AA, Tawahina B, Vostanis P. Effectiveness of student mediation program to decrease behavioural and emotional problems in Palestinian children affected by war and trauma in the Gaza strip. Arabpsynet E Journal. 2009;24(1):50-5.

35. Barron I. Randomized control trial of a CBT trauma recovery program in Palestinian schools. J Loss Trauma. 2013;18(4):306-21. This design took a mixed-methods approach where the children's experience of the intervention was a core focus of the publication. Aiding in the future design of programs for children affected by armed conflict.

36.• Betancourt TS, Newnham EA, Brennan RT, Verdeli H, Borisova I, Neugebauer R, et al. Moderators of treatment effectiveness for waraffected youth with depression in northern Uganda. J Adolesc Health: Off Publ Soc Adolesc Med. 2012;51(6):544-50. Reported large effect sizes on specific subgroups. However the intervention also demonstrated a negative effect on male non- abducted subjects. Therefore the intervention improved some childrens mental health but undermined natural recovery of others. This demonstrates the need for tailored interventions.

37. Peltonen K, Qouta S, El Sarraj E, Punamaki R-L. Effectiveness of school-based intervention in enhancing mental health and social functioning among war-affected children. Traumatology. 2012;18(4):37-46.

38. Staples JK, Abdel Atti JA, Gordon JS. Mind-body skills groups for posttraumatic stress disorder and depression symptoms in Palestinian children and adolescents in Gaza. Int J Stress Manag. 2011;18(3):246-62.

39. Castro FG, Barrera Jr M, Martinez Jr CR. The cultural adaptation of prevention interventions: resolving tensions between fidelity and fit. Prev Sci: Off J Soc Prev Res. 2004;5(1):41-5.

40. Sachs JD, McArthur JW. The millennium project: a plan for meeting the millennium development goals. Lancet (London, England). 2005;365(9456):347-53.

41. Biddle SJ, Asare M. Physical activity and mental health in children and adolescents: a review of reviews. Br J Sports Med. 2011;45(11):886-95.

42. Eime RM, Young JA, Harvey JT, Charity MJ, Payne WR. A systematic review of the psychological and social benefits of participation in sport for children and adolescents: informing development of a conceptual model of health through sport. Intern J Behav Nut Physical Act. 2013;10:98.

43. Ekeland E, Heian F, Hagen K, Coren E. Can exercise improve self esteem in children and young people? A systematic review of randomised controlled trials. Br J Sports Med. 2005;39(11):792.

44. Ertl V, Pfeiffer A, Schauer E, Elbert T, Neuner F. Communityimplemented trauma therapy for former child soldiers in Northern Uganda: a randomized controlled trial. Jama. 2011;306(5):503-12.

45. International Law Association (ILA). The Hague Conference. Use of force. Netherlands; 2010.

46. World Health Organization. Promoting mental health: concepts, emerging evidence, practice: report of the World Health Organization, Department of Mental Health and Substance Abuse in collaboration with the Victorian Health Promotion Foundation and the University of Melbourne Geneva; 2005. 